\title{
APORTE DESDE EL DERECHO INTERNACIONAL PRIVADO A LA LEGISLACIÓN PARAGUAYA: LA LEY No 5393/15 "SOBRE EL DERECHO APLICABLE A LOS CONTRATOS INTERNACIONALES"
}

Hugo Esteban Estigarribia Gutiérrez*

\section{INTRODUCCIÓN}

Los contratos internacionales constituyen una pieza esencial en el desarrollo de la actividad comercial en el mundo. Desde una visión jurídica ellos plantean una cuestión particular que va cambiando en forma rápida y sensible en sus áreas de afectación. Son considerados el lugar natural para la expresión de la voluntad de las partes, siendo, los contratos, regulados por los Estados nacionales, en sus respectivas legislaciones internas y por las organizaciones internacionales y supranacionales, con vigencia entre sus miembros por medio de tratados y convenios internacionales después incorporados como tales en los respectivos países. En el sector privado, al igual de los particulares contratantes, han empezado a tener trascendencia varias instituciones que funcionan para reglamentar, para proveer servicios y para prevenir y resolver conflictos. Las rígidas normas creadas por los Estados y los organismos internacionales conviven con otras creadas tanto por instituciones privadas como públicas en una relación no permanentemente armónica. Un importante número de conflictos asociados a los contratos internacionales son sometidos a arbitraje, transformando, profundamente, la misión asignada a la administración de justicia en la materia. Se buscan contestaciones en todos los ámbitos de producción jurídica y principalmente en la legislación local, facilitando las transacciones comerciales. Es por ello que, como producto de trabajos hechos por académicos paraguayos en el campo del Derecho Internacional Privado en sus reuniones y participaciones en eventos * Universidad Nacional de Asunción, Paraguay. E-mail: hestigarribia@gmail.com
Recibido: 10/02/2017. Aceptado: 3/03/2017. 
internacionales, los cuales mantenían vínculos profesionales anteriores con nosotros, hemos decidido, incorporar esas regulaciones modernas a nuestra legislación nacional, conforme a nuestros antecedentes de formación profesional en esa área y desde la condición de Senador de la Republica que ostentábamos, a través de un proyecto de ley sobre contratos internacionales que facilite su aplicación en el Paraguay, como centro geográfico y jurídico del MERCOSUR, dejando de lado las rígidas normas establecidas en su Código Civil, y sumando esta norma a otras ya vigentes, como la Ley de Maquila y de Fomento a las Inversiones, para hacer aún más atractivo el país como plaza fuerte de inversiones y comercio regional de Sudamérica. Así nació la actual Ley No 5393/15 "Sobre el derecho aplicable a los contratos internacionales".

\section{CRONOLOGÍA DE LA CREACIÓN Y PUESTA EN VIGENCIA DE LA LEY 5393/15}

En cumplimiento del Artículo 203 de la Constitución Nacional el que suscribe ha presentado un proyecto de Ley "Sobre el Derecho Aplicable a los Contratos Internacionales", en fecha 9 de mayo de 2013, con el que se pretendió dotar al Paraguay de un cuerpo normativo que contenga los "Principios" sobre el derecho aplicable a la contratación transfronteriza, principios que fueron aprobados recientemente por la Conferencia de La Haya de Derecho Internacional Privado, máximo organismo codificador en la especialidad.

Tras un año y siete meses de estudio, el proyecto de ley fue sancionado por el Poder Legislativo el 4 de diciembre de 2014, promulgado por el Poder Ejecutivo el 14 de enero de 2015, publicado en la Gaceta Oficial de la República del Paraguay el 20 de enero de 2015, siendo ley Ley 5393/15 "Sobre el derecho aplicable a los contratos internacionales",vigente en todo el territorio de la República desde el 20 de enero de 2015, conforme al artículo 213 y concordantes de la Constitución Nacional del Paraguay.

\section{RAZONES PARA LA PRESENTACIÓN DEL PROYECTO DE LEY SOBRE CONTRATOS INTERNACIONALES}

Con este proyecto de ley se pretendió dotar al Paraguay de un cuerpo normativo que contenga los "Principios" sobre el derecho aplicable a la contratación transfronteriza, principios que fueron aprobados recientemente por la Conferencia de La Haya de Derecho Internacional Privado, máximo organismo codificador en la especialidad.

Que, los principios mencionados con antecedencia, entre otras aplicaciones, deben servir de inspiración a legisladores nacionales para la elaboración de leyes que uniformicen la regulación de la materia, lo 
que resulta altamente deseable para lograr una mayor predictibilidad en las relaciones comerciales internacionales.

El Paraguay, al momento de la presentación de este proyecto de ley contaba con un régimen anacrónico en materia del derecho aplicable a la contratación para el comercio transfronterizo. Gran parte de las disposiciones vigentes, contenidas en el Código Civil, se inspiraban en vetustos tratados o códigos decimonónicos, absolutamente de contramano con las necesidades mercantiles del mundo de hoy.

Asimismo que el Paraguay ha tenido participación activa en la elaboración de dicho instrumento, tanto en la representación oficial del país ante la Comisión Especial formada en el organismo de La Haya para dicho fin, como a través de la participación de un connacional en el Grupo de Expertos que por varios años elaboró el proyecto de "Principios".

\section{CARACTERÍSTICAS DE LA ACTUAL LEY VIGENTE}

Esta novedosa ley prácticamente reproduce, en gran medida, el texto aprobado en la referida Conferencia de La Haya, lo cual deviene altamente aconsejable, con algunas adecuaciones que resultan convenientes, para ponerla en sintonía también con la Convención de México de 1994 sobre el derecho aplicable a los contratos internacionales, aprobada en el marco delas Conferencias Interamericanas Especializadas de Derecho Internacional Privado (CIDIPs) de la Organización de los Estados Americanos, cuyo texto a su vez sirvió de inspiración para la elaboración de los "Principios de La Haya" arriba referidos. De hecho, la citada Convención de México puede ser incorporada vía ratificación, o vía la adopción de una ley que recoja el espíritu de su regulación -como ya ocurrió en Latinoamérica-.

En la ley se incorporan las bondades de la Convención de México, a la vez que los adelantos recogidos en el instrumento flamantemente aprobado en La Haya.

La nueva Ley así permite claramente acordar la aplicación de la ley que las partes estimen más conveniente para sus contratos internacionales, otorgando de esta manera mayor previsibilidad y confianza a las transacciones comerciales internacionales.

La Ley se encuentra basada en gran medida en el borrador de los Principios de La Haya sobre la Elección de la Ley Aplicable a los Contratos Internacionales (Principios de La Haya). No obstante, se observan algunas diferencias introducidas por el Congreso durante las discusiones sobre el proyecto de Ley.

Incluye una provisión sobre la armonización equitativa de intereses, la cual es tal vez la diferencia más resaltante con los Principios de La Haya. 


\section{5. ÁMBITO DE APLICACIÓN DE LA LEY}

Regula la elección del derecho aplicable en los contratos internacionales cuando cada una de las partes actúa en el ejercicio de su negocio o profesión.

Reconoce la posibilidad de acordar la aplicación de "normas de derecho", i.e. derecho no estatal o de soft law contiene provisiones sobre leyes de policía y orden público, que en general prevalecen sobre el acuerdo de las partes. contiene provisiones sobre leyes de policía y orden público, que en general prevalecen sobre el acuerdo de las partes.

No se aplica a: contratos de consumo, contratos de trabajo, contratos de franquicia, representación, agencia y distribución.

Aplicación a los contratos internacionales con la más amplia interpretación posible, con exclusión de los contratos en los que todos los elementos relevantes estén vinculados con un solo Estado (contratos nacionales).

\section{CUESTIONES NO COMPRENDIDAS EN LA LEY}

La capacidad de las personas físicas

Los acuerdos de arbitraje y de elección de foro.

Las sociedades $\mathrm{u}$ otras asociaciones y los fideicomisos.

Los procedimientos de insolvencia.

contratos de agencia, distribución internacional

La cuestión de saber si un representante puede obligar, frente a terceros, a la persona en nombre de la cual pretende actuar.

\section{LIBERTAD DE ELECCIÓN}

Un contrato se elige por el derecho elegido por las partes

Las partes pueden elegir:

El derecho aplicable a la totalidad o una parte del contrato; y,

Distintos derechos para diferentes partes del contrato, en la medida en que estos sean claramente distinguibles

\section{ARTÍCULOS DEL CÓDIGO CIVIL PARAGUAYO DEROGADOS POR LA LEY 5393/15}

Artículo 14 ( Capacidad de derecho)

Artículo 17 ( Lex loci executionis: derecho de crédito)

Artículo 297 ( Régimen legal de los actos jurídicos)

Artículo 687 ( Lugar de celebración de los contratos)

Artículo 699 ( Leyes aplicables a la forma de los contratos según lugar, presencia y ausencia) 


\section{IMPLICANCIAS DE LA NUEVA LEY}

Es muy importante promover la sanción y promulgación de leyes, como esta, que apoyen e incentiven el comercio regional y la inversión en una forma que otorguen ventajas apetecibles a una persona o grupo inversor para invertir en un país determinado y no en otro.

La vigencia de la Ley 5393/15 concede al Paraguay el rol de "país de avanzada" - de acuerdo al reconocimiento hecho por la misma Conferencia de La Haya de Derecho Internacional Privado - en la incorporación legislativa de los Principios al derecho que estudia el Derecho Internacional Privado, como ha ocurrido por ejemplo con las recientes X Jornadas de la Asociación Americana de Derecho Internacional Privado ( ASADIP), llevadas a cabo en la ciudad de Buenos Aires, Argentina, los días 10 y11 noviembre, con el tema "Los contratos internacionales entre la libertad de las partes y el control de los poderes públicos" y en otros eventos llevados a cabo en el país sobre el tema

\section{CONCLUSIONES}

La Ley 5393/15 "Sobre el derecho aplicable a los contratos internacionales" constituye un salto a la modernidad de la legislación paraguaya, en el campo de los contratos internacionales y las inversiones que se darán bajo su marco, siendo citado como un ejemplo a seguir, en toda la región.

Todavía es una incógnita la manera en que los tribunales y árbitros en el Paraguay aplicarán e interpretarán la reciente legislación, pero será, sin duda alguna un punto de inflexión en el comercio trasnacional para el país.

Esperemos que el debate jurídico y académico se siga acentuando con respecto a esta norma y que la misma sirva a sus objetivos de incrementar, positiva y aceleradamente, el comercio y las inversiones internacionales en el Paraguay, otorgando seguridad jurídica a los potenciales y reales comerciantes e inversores extranjeros que se acercan al país.

\section{RESUMEN BIOGRÁFICO}

Hugo Esteban Estigarribia Gutierrez es Abogado constitucionalista, internacionalista y romanista. Miembro de la Corte Permanente de Arbitraje de la Haya (Grupo Nacional) (2011-2017). Socio Fundador y Principal de Estigarribia \& Asociados, Estudio Jurídico (07/2013). Especializado en Derecho Constitucional, Derecho Internacional, Arbitraje Jurídico y Técnica Legislativa. Senador de la Nación de la República del Paraguay (2008-2013). Miembro Suplente del Tribunal de Revisión del MERCOSUR (2004-2008), Convencional Constituyente 
Titular para la redacción de la Constitución Nacional (1991-1992). Presidente (2009-2010) y Miembro (2008-2013) de las Comisiones de Asuntos Constitucionales, Defensa Nacional y Fuerza Pública: Vicepresidente (2009-2010) de Legislación y Codificación: de Obras Publicas y de Lucha Contra el Narcotráfico y Delitos Conexos (20122013) del Senado de Paraguay. Presidente de la Comisión Especial de Reforma del Reglamento Interno dela Cámara de Senadores (2011-2012) Abogado y Notario Público, Mejor graduado galardonado con Medalla de Oro en ambas carreras, Facultad de Derecho, Universidad Nacional de Asunción (UNA) (1989 y 1990). Maestría en Ciencias Políticas (UNA) (1996). Postgrado en Administración Pública, Shenandoah University, Virginia, EEUU (2001). Ex becario de la OEA para estudios de Maestría en EE.UU. (2001, 2002). LLM, Máster en Derecho en Estudios Legales Internacionales, con especialización en Organismos Internacionales y Derecho Internacional de Negocios, American University, Washington DC, EE.UU. (2002). LLM, Máster en Derecho en Leyes y Gobierno, con especialización en Derecho Constitucional y Derechos Civiles, American University, Washington DC, EE.UU. (2003). Candidato a Doctor en Derecho, con tesis doctoral en elaboración, por la Facultad de Derecho (UNA). Profesor de las materias "Derecho Romano, Derecho Constitucional y Derecho Político" en las Facultades de Derecho de las Universidades Nacional de Asunción, Católica, Americana y Uninorte del Paraguay y de la materia "Escuelas del Pensamiento Político" de la carrera de Relaciones Internacionales y de la materia "Derecho Administrativo" en la Maestría y Diplomado en Gobierno y Gerencia Pública de la Universidad Americana. Profesor del Instituto de Altos Estudios Estratégicos (IAEE) del Ministerio de Defensa Nacional. 